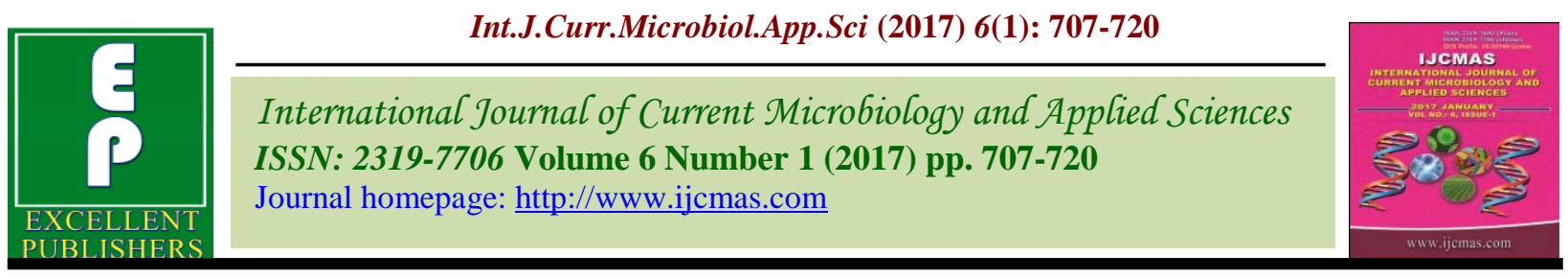

Original Research Article

http://dx.doi.org/10.20546/ijcmas.2017.601.085

\title{
Phytochemical Screening and In vitro Antimicrobial Properties of Crude Leaf Extracts of Wrightia tinctoria R.Br.
}

\author{
Sravanthi Maddila and K.P.J. Hemalatha* \\ Department of Biochemistry, Andhra University, Visakhapatnam, 530003, \\ Andhra Pradesh, India \\ *Corresponding author
}

\section{A B S T R A C T}

Keywords

Wrightia tinctoria, phytochemical

screening,

antimicrobial activity, minimum inhibitory concentration (MIC).

Article Info

Accepted:

29 December 2016

Available Online:

10 January 2017
The crude hexane, ethyl acetate and aqueous leaf extracts of medicinal plant Wrightia tinctoria $\mathrm{R}$.Br. were evaluated for in vitro antimicrobial activity against selected bacterial and fungal strains. Preliminary phytochemical screening of the three crude leaf extracts revealed the presence of phenols, alkaloids, tannins, flavonoids, terpenoids and sterols. The extracts were screened against three Gram positive strains (Bacillus subtilis, Bacillus licheniformis and Streptococcus pneumoniae), two Gram negative strains (Escherichia coli and Sphingomonas sanguinis) and against three fungal strains (Aspergillus flavus, Aspergillus niger and Candida albicans). Antimicrobial activity of these crude extracts was determined using Agar well diffusion method. Agar broth and Potato dextrose broth dilution method was used to determine the minimum inhibitory concentration. Ampicillin and Flucanazole were used as standards for bacteria and fungi respectively. The results of in vitro antimicrobial activity showed that hexane, ethyl acetate and aqueous crude leaf extracts were active on all microbial strains tested at different concentrations, with hexane leaf extract exhibiting more activity. Results obtained from the present study showed that the leaf extracts of Wrightia tinctoria R.Br. have considerable antimicrobial activity and hence, they may be used for further extraction and isolation of antimicrobial compounds which may find a place in medicine industry as constituents of antibiotics.

\section{Introduction}

The use of plant and plant derived substances to fight against microorganisms is now on the increase due to the development of resistance against chemical antibiotics by microbial strains, occurrence of undesirable side effects from some chemically synthesized drugs, scarcity and high cost of new generation antibiotics (Masibo and He, 2009), biodegradation time of synthetic materials compared to natural or organic substances with faster degradation time (Lewis and Elvin Lewis, 1995).
The effectiveness of most common antibiotics has been limited due to the emergence of multi-drug resistant bacterial strains. This development has prompted science to search for new antibiotics to take up the challenge of resistance strains of microbial pathogens. The search for antibiotics largely depends on medicinal plants as raw materials (Doughari and Manzara, 2008). Investigations on medicinal plants have revealed the presence of bioactive substances that can be utilized to solve health needs. A variety of plants or 
materials derived from plants have been used for the prevention and treatment of diseases virtually in all cultures (Adesina et al., 2010).

The medicinal potential (antimicrobial, antioxidant, anticancer, antimalaria, immunomodulatory, etc.) attributed to plants has been linked to the presence of bioactive constituents also known as phytochemicals in these plants. These bioactive substances have been found to produce definite physiological action on the human body (Akinmoladun et $a l .$, 2007). These bioactive substances include alkaloids, essential oils, saponins, tannins, flavonoids, terpenoids and phenolic compounds (Edeoga et al., 2005 and Mungole et al., 2010). Antimicrobial properties are expressed by most of plants that are composed of tannins, terpenoids, glycosides, alkaloids, saponins, flavonoids, polyphenols and coumarins.

Wrightia tinctoria R.Br. (FamilyApocynaceae) is commonly known as 'Kudi', 'Dudhi', and 'Indrajao' 'Easter tree' and 'Jaundice curative tree'. Wrightia tinctoria $\mathrm{R} . \mathrm{Br}$ is available in wild habitats and has high medicinal value in Indian indigenous system of medicine. It used in modern medicine as raw material for important drugs as well as food and occupy a very significant place. This plant is a rich source of ecologically developed secondary metabolites with potential remedies for different ailments.

The juice of the tender leaves is used efficaciously in jaundice. It is reported to possess aphrodisiac, anthelmintic, anti inflammatory, astringent and antimicrobial properties. The crushed fresh leaves when filled in the cavity of decayed tooth relieve toothache. Bark and seeds are used to cure bilious infections, psoriasis, leprosy, asthma and various skin diseases (Veerapur et al., 2004). It has anti-dandruff properties and hence is used in hair oil preparations.
An oil, 777 prepared out of the fresh leaves of the plant has been assigned to analgesic, antiinflammatory and antipyretic activities (Ghosh et al., 1985), and to be effective in the treatment of psoriasis (Krishnamurthi et al., 1981). The phytochemical research based on ethno-pharmacological information is generally considered an effective approach in the discovery of new anti-infective agents from higher plants (Bigoniya and Rana, 2010). The present investigation designed to screen antimicrobial activity of Wrightia tinctoria against some microbial pathogens and its phytochemical constituents. The current in vitro antimicrobial study was aimed at validating the effect of Wrightia tinctoria for their antimicrobial activity against bacteria and fungi. In addition, phytochemical profiles were also evaluated to correlate possible biological activity of the plant.

\section{Materials and Methods}

\section{Collection of plant material}

The leaves of the plant under study, W.tinctoria were collected from Andhra University campus, Visakhapatnam. The leaves were authenticated by Prof. M. Venkaiah, Department of Botany, Andhra University, Visakhapatnam, Andhra Pradesh, India.

\section{Preparation of plant extract}

The leaves were washed and shade dried at room temperature. The dried leaf material was powdered finely and extracts were prepared.

Hexane and ethyl acetate extract: The dried, powdered leaf material was macerated separately in hexane and ethyl acetate for $72 \mathrm{~h}$ with occasional stirring. The mixture was filtered and the filtrate was evaporated to dryness under reduced pressure in a rotary vacuum evaporator (Heidolph, Hyderabad) at 
$40^{\circ} \mathrm{C}$. Solvent elimination through reduced pressure of hexane extract resulted in $3 \% \mathrm{w} / \mathrm{w}$ yield and $2.7 \% \mathrm{w} / \mathrm{w}$ yield for ethyl acetate leaf extract for W.tinctoria R.Br. The extracts were then kept in desiccators at room temperature prior to use.

Aqueous extract: One gram of fresh leaves were weighed and ground in a chilled mortar and pestle with $10 \mathrm{ml}$ buffer solution (Tris $\mathrm{HCl} 0.05 \mathrm{M}, \mathrm{pH} 7.0$ consisting of $3 \mathrm{mM}$ $\mathrm{MgCl}_{2}, 1 \mathrm{mM}$ EDTA). The extract was centrifuged at $4{ }^{\circ} \mathrm{C}$ for $10 \mathrm{~min}$ at $5000 \mathrm{rpm}$ and the supernatant obtained was used for the determination of enzymatic and non enzymatic antioxidants.

HE indicates crude hexane leaf extract, EE indicates crude ethyl acetate leaf extract and $\mathrm{AE}$ indicates crude aqueous leaf extract.

Screening of phytochemicals and antimicrobial activity

The following tests were performed with the plant leaf extracts to detect various phytochemicals present in them according to standard procedures (Tripathi and Patel, 2007).

Detection of alkaloids by Mayer's test: To a few ml of extract, a drop or two of Mayer's reagent was added by the side of the test tube. A white or creamy precipitate indicates the test as positive.

Detection of carbohydrates by Molisch's test: To $2 \mathrm{ml}$ of plant extract, two drops of alcoholic solution of $\alpha$ - naphthol was added, the mixture was shaken well and $1 \mathrm{ml}$ of conc. $\mathrm{H}_{2} \mathrm{SO}_{4}$ was added slowly along the sides of the test tube and allowed to stand. A violet ring indicates the presence of carbohydrates.

Detection of saponins by Froth test: To $2 \mathrm{ml}$ of plant extract, $2 \mathrm{ml}$ of distilled water was added. The suspension was shaken in a graduated cylinder for $15 \mathrm{~min}$. A $2 \mathrm{~cm}$ layer of foam indicates the presence of saponins.

Detection of phytosterols by LibermannBurchard's test: One ml of plant extract was dissolved in $2 \mathrm{ml}$ acetic anhydride. To this, one or two drops of conc. $\mathrm{H}_{2} \mathrm{SO}_{4}$ were added slowly along the sides of the test tube. An array of colour changes shows the presence of phytosterols.

Detection of Phenols by Ferric chloride test: To $1 \mathrm{ml}$ of plant extract, $2 \mathrm{ml}$ of distilled water was added. To this, few drops of neutral $5 \%$ ferric chloride solution was added. A dark green colour indicates the presence of phenolic compounds.

Detection of flavonoids by Alkaline reagent test: To $2 \mathrm{ml}$ of plant extract, $1 \mathrm{ml}$ of $2 \mathrm{~N}$ sodium hydroxide was added. Presence of yellow colour indicates the presence of flavonoids.

Detection of tannins by Gelatin Test: To 1 $\mathrm{ml}$ of plant extract, $2 \mathrm{ml}$ of $5 \%$ ferric chloride was added. Formation of dark blue or greenish black indicates the presence of tannins.

Test for terpenoids by Salkowski test: To $0.5 \mathrm{ml}$ of extract, $2 \mathrm{ml}$ of chloroform was added and conc. $\mathrm{H}_{2} \mathrm{SO}_{4}$ was added carefully. Formation of reddish brown colour at the interface indicates the presence of terpenoids.

Test for quinones: To $1 \mathrm{ml}$ of extract, $1 \mathrm{ml}$ of conc. $\mathrm{H}_{2} \mathrm{SO}_{4}$ was added. Formation of red colour indicates presence of quinones.

Test for coumarins: To $1 \mathrm{ml}$ of extract, $1 \mathrm{ml}$ of $10 \% \mathrm{NaOH}$ was added. Formation of yellow colour indicates presence of coumarins. 


\section{Preparation of Nutrient agar for bacteria}

The ingredients (Peptone, Yeast extract, $\mathrm{NaCl}$, Agar-agar) were mixed and dissolved by heating. The $\mathrm{pH}$ was adjusted to $7.5 \pm 0.1$. The broth was solidified by adding agar and sterilized by autoclaving at $121^{\circ} \mathrm{C}$ for $15 \mathrm{~min}$ and poured into sterile petri dishes. After setting, the media was preserved in refrigerator for use.

\section{Preparation of Potato dextrose agar for fungi}

Potato infusion was prepared by boiling 200 gm sliced, unpeeled potatoes in one litre distilled water for $30 \mathrm{~min}$. It was filtered through cheesecloth and the effluent, potato infusion, was saved. The other ingredients (Dextrose, Agar-agar) were mixed and boiled to dissolve, then autoclaved for $15 \mathrm{~min}$ at $121^{\circ} \mathrm{C}$. Final $\mathrm{pH}$ was adjusted to $5.6 \pm 0.2$. Ten to $20 \mathrm{ml}$ of medium was poured into petri dishes under sterile conditions.

\section{Test organisms for antimicrobial studies}

The microbial strains Bacillus subtilis (MTCC 121), Bacillus licheniformis (MTCC 429), Streptococcus pneumoniae (MTCC 2672), Escherichia coli (MTCC 118), Sphingomonas sanguinis (MTCC 5495), Aspergillus niger (MTCC 2723), Aspergillus flavus (MTCC 4633), Candida albicans (MTCC 227) were collected from Microbial Type Culture Collection (MTCC), Institute of Microbial Technology, Chandigarh, India.

\section{Determination of Antimicrobial Activity}

Active cultures were generated by inoculating a loopful of culture in separate $100 \mathrm{ml}$ nutrient/potato dextrose broth and incubating on a shaker at $37^{\circ} \mathrm{C}$ overnight. The cells were harvested by centrifuging at $4000 \mathrm{rpm}$ for 5 min, washed with normal saline, spun at 4000 rpm for 5 min again and diluted in normal saline to obtain $5 \times 10^{5} \mathrm{CFU} / \mathrm{ml}$.

\section{Antibacterial activity}

The condensed leaf extracts were subjected to antibacterial assay using the agar well diffusion method of Murray (1995) modified by Olurinola (1996).

Nutrient agar $(20 \mathrm{ml})$ was dispensed into sterile universal bottles, inoculated with 0.2 $\mathrm{ml}$ of cultures, mixed gently and poured into sterile petri dishes. After setting, a number 3cup borer $(6 \mathrm{~mm})$ diameter was properly sterilized by flaming and used to make four uniform wells in each petri dish. The dilution medium for plant extract is dimethyl sulphoxide (DMSO), which is used as negative control. The wells were filled with plant leaf extracts containing $250 \mu \mathrm{g}$ and 500 $\mu \mathrm{g} / 50 \mu \mathrm{l} / \mathrm{well}$ and allowed for diffusion of plant extract for $45 \mathrm{~min}$. The plates were incubated at $37^{\circ} \mathrm{C}$ for $24 \mathrm{~h}$ for bacteria. Ampicillin was used as positive control. The inhibition zones were measured with antibiotic zone scale in $\mathrm{mm}$ and the experiment was carried out in triplicates.

\section{Antifungal activity}

The condensed leaf extracts were subjected to antifungal assay using the agar well diffusion method of Perez et al., (1990).

The cultures of $48 \mathrm{~h}$ old grown on potato dextrose agar (PDA) were used for inoculation of fungal strains on PDA plates. An aliquot $(0.2 \mathrm{ml})$ of inoculum was introduced to molten PDA and poured into a petri dish by pour plate technique. After solidification, the appropriate wells were made and they were filled with each leaf extract containing $250 \mu \mathrm{g}$ and $500 \mu \mathrm{g} / 50$ $\mu 1 /$ well and allowed for diffusion of the plant extracts for $45 \mathrm{~min}$. The dilution medium for 
plant extract is dimethyl sulphoxide (DMSO), which was used as negative control. Flucanazole was used as positive control. The plates were incubated at $25^{\circ} \mathrm{C}$ for $48 \mathrm{~h}$. The zones of inhibition were measured as described earlier.

\section{Minimum inhibitory concentration (MIC) assays}

Minimum Inhibitory Concentration (MIC) of the hexane, ethyl acetate and aqueous leaf extracts of W.tinctoria were determined according to the method of Elizabeth (2001).

A series of two fold dilution of each leaf extract, ranging from $1-5 \mathrm{mg} / \mathrm{ml}$, was prepared. After sterilization, the medium was inoculated with the aliquots of culture containing approximately $5 \times 10^{5} \mathrm{CFU} / \mathrm{ml}$ of each organism of $24 \mathrm{~h}$ slant culture in aseptic condition and transferred into sterile 6 inch diameter petri dishes and allowed to set at room temperature for about $10 \mathrm{~min}$ and then kept in a refrigerator for $30 \mathrm{~min}$. After the media was solidified, wells were made and different concentrations of each leaf extract ranging from $1-5 \mathrm{mg} / \mathrm{ml}$ were added to the wells of each petri dish. The blank plates were without plant extracts. Inhibition of the growth of the organism in the plates containing plant extract was judged by comparison with the growth in the control plates. The MIC was determined as the lowest concentration of the hexane, ethyl acetate and aqueous leaf extracts of W.tinctoria inhibiting visible growth of each organism on the agar plate. MIC for fungal strains was also determined in a similar manner by using spores/cultures and incubating for $48 \mathrm{~h}$.

\section{Results and Discussion}

\section{Phytochemical screening}

The qualitative analysis of hexane, ethyl acetate and aqueous leaf extracts of Wrightia tinctoria showed the presence of various phytochemical constituents like tannins, phenols, flavonoids, alkaloids, steroids, terpenoids etc. (Table -1$)$. The presence of high amount of active phytoconstituents such as phenols, alkaloids, terpenes etc., has made the tested leaf extracts a good source for more exploration in pharmacological activity. The outcome of present study suggests that W.tinctoria may prove to be quality product for the production of useful therapeutics.

Previous study performed on preliminary phytochemical screening of the methanolic root extracts of W.tinctoria has reported the presence of phenols, tannins, saponins, terpenoids, emodins, coumarins and fatty acids (Subhashini et al., 2014). Vedhanarayanan et al., (2013) reported that the preliminary phytochemical screening of ethanol leaf extract of W.tinctoria has shown the presence of flavonoids, phenols, steroids and tannins, whereas chloroform leaf extract revealed the presence of alkaloids, saponins, steroids and tannins and methanolic leaf extract showed the presence of flavonoids, phenols and steroids.

\section{Antimicrobial activity}

The crude hexane, ethyl acetate and aqueous leaf extracts of Wrightia tinctoria were evaluated for antimicrobial activity against selected bacterial and fungal strains by assessing the minimum inhibitory concentrations and the microbicidal effect of W.tinctoria was further visualized as inhibition zone by treating the test organisms with leaf extracts and then spreading the cells on agar plates.

\section{Antibacterial activity}

All the three crude leaf extracts of Wrightia tinctoria exhibited significant in vitro antibacterial activity against all the tested bacterial strains at a concentration of 500 
$\mu \mathrm{g} / 50 \mu \mathrm{l} \quad$ (Table - 2). Among the tested extracts, HE exhibited more antibacterial activity when compared to the other extracts. The zones of inhibition recorded were $26 \mathrm{~mm}$, $25 \mathrm{~mm}, \quad 24 \mathrm{~mm}, 23 \mathrm{~mm}$ and $20 \mathrm{~mm}$ against B.subtilis, B.licheniformis S.pneumoniae, E.coli and S.sanguinis respectively by HE. On the other hand, growth of B.subtilis, B.licheniformis S.pneumoniae, E.coli and S.sanguinis was affected moderately with zones of inhibition recorded as $25 \mathrm{~mm}, 24 \mathrm{~mm}, 20 \mathrm{~mm}, 22 \mathrm{~mm}$ and $18 \mathrm{~mm}$ respectively by EE of W.tinctoria at a concentration of $500 \mu \mathrm{g} / 50 \mu 1$. The effect of growth on bacterial strains by $\mathrm{AE}$ was less when compared to the other two leaf extracts with zones of inhibition recorded as $12 \mathrm{~mm}$, $20 \mathrm{~mm}, 18 \mathrm{~mm}, 12 \mathrm{~mm}$ and $10 \mathrm{~mm}$ against B.subtilis, B.licheniformis S.pneumoniae, E.coli and S.sanguinis respectively. Antibacterial activity of $\mathrm{HE}$ of W.tinctoria exhibiting maximum zone of inhibition was presented in Figure - I.

Minimum inhibitory concentration of W.tinctoria for its antibacterial activity was presented in Table -3 . The minimum inhibitory concentrations (MIC) of HE of W.tinctoria leaf extract for B.subtilis, B.licheniformis, S.pneumoniae, E.coli and S.sanguinis was found to be $2 \mathrm{mg} / \mathrm{ml}, 2.2$ $\mathrm{mg} / \mathrm{ml}, 2.3 \mathrm{mg} / \mathrm{ml}, 2.5 \mathrm{mg} / \mathrm{ml}$ and $3 \mathrm{mg} / \mathrm{ml}$ respectively. The MIC of EE was observed to be in the range of $2.2-3.3 \mathrm{mg} / \mathrm{ml}$ whereas for $\mathrm{AE}$ it was observed to be in the range of 3 $4.6 \mathrm{mg} / \mathrm{ml}$.

\section{Antifungal activity}

The three crude leaf extracts of Wrightia tinctoria were also tested for antifungal activity along with positive control, Flucanazole. All the extracts exhibited significant in vitro antifungal activity against A.niger, A. flavus and C.albicans at a concentration of $500 \mu \mathrm{g} / 50 \mu \mathrm{l}$ (Table -4 ).
The highest zone of inhibition was observed to be $25 \mathrm{~mm}$ against Candida albicans followed by A.niger - $22 \mathrm{~mm}$ and A. flavus $20 \mathrm{~mm}$ by HE. Moderate inhibition was observed by $\mathrm{EE}$ with zones of inhibition recorded as $19 \mathrm{~mm}, 18 \mathrm{~mm}$ and $23 \mathrm{~mm}$ against A.flavus, A.niger and C.albicans respectively. The fungal strains were less susceptible to AE of Wrightia tinctoria with zones of inhibition recorded as $8 \mathrm{~mm}, 16 \mathrm{~mm}$ and $20 \mathrm{~mm}$ against A.flavus, A.niger and C.albicans respectively. Antifungal activity of HE of W.tinctoria exhibiting maximum zone of inhibition was presented in Figure - II.

Minimum inhibitory concentration of W.tinctoria for its antifungal activity was presented in Table - 5. The minimum inhibitory concentration (MIC) of $\mathrm{HE}$ of W.tinctoria leaf for A.flavus was found to be 3 $\mathrm{mg} / \mathrm{ml}$, for A.niger - $2.8 \mathrm{mg} / \mathrm{ml}$, C.albicans $2.2 \mathrm{mg} / \mathrm{ml}$. The MIC of EE was observed to be in the range of $2-3.1 \mathrm{mg} / \mathrm{ml}$ whereas for $\mathrm{AE}$ were observed to be in the range of 3 $4.8 \mathrm{mg} / \mathrm{ml}$.

In the past two decades, a number of studies have been conducted on medicinal herbs in different countries to prove their efficiency as antimicrobial agents. Pharmacological industries have produced a number of new antibiotics in the last three decades but still the resistance to these drugs by microorganisms has increased. In general, bacteria have the genetic ability to transmit and acquire resistance to drugs, which are utilized as therapeutic agents (Cohen, 1992). This may be due to the increase in incidence of multiple drug resistance. Microbial resistance towards antimicrobial agents has been reported (Truiti et al., 2003).

Higher plants mainly produce antimicrobial compounds for their defense mechanism against infections. Their secondary metabolites or phytochemicals represent a large reservoir of structural moieties which 
work together exhibiting a wide range of biological activities. Phytochemicals act as antimicrobial agents by inhibiting peptidoglycan synthesis, damaging microbial membrane structures and modifying bacterial membrane surface hydrophobicity (Rasooli et al., 2008). The results of antimicrobial activity on W.tinctoria were in acceptance with these reports.

The result obtained from the above study proves antimicrobial activity of W.tinctoria. It can be observed from above results that inhibition was high against Gram positive bacteria than Gram negative bacteria due to the presence of an effective permeability barrier in Gram negative bacteria, comprising of an outer membrane with high content of cell wall lipopolysaccharides, which restricted the penetration of phytochemical amphipathic compounds and multi drug resistance pumps that extrude toxins across the barrier (Adesokan et al., 2007). The reason for high MIC values exhibited by the crude extract might be because the active principle compound was present in very low concentration and also the active compound was present along with other secondary metabolites which might restrict the inhibitory activity against microbial strains in the crude extract.

Previous reports also showed the antimicrobial activity of W.tinctoria. Kannan et al., (2006) reported the antimicrobial activity of W.tinctoria hexane, methanol and ethanol leaf extracts against dermatophytes. Methanol and ethanol extracts showed antibacterial activity. The MIC was reported to be $0.5 \mathrm{mg} / \mathrm{ml}$ for B.subtilis and $0.25 \mathrm{mg} / \mathrm{ml}$ for Staphylococcus aureus.

Moorthy et al., (2012) reported the MIC of methanol and petroleum ether leaf extracts of W.tinctoria. The MIC was reported to be 512 $\mu \mathrm{g} / \mathrm{ml}$ against S.aureus and C.albicans by methanolic leaf extract whereas MIC was 512 $\mu \mathrm{g} / \mathrm{ml}$ and $1024 \mu \mathrm{g} / \mathrm{ml}$ against S.aureus and C.albicans by petroleum ether leaf extract respectively. In the present study, it can be observed that the MIC of W. tinctoria hexane leaf extract against $B$. subtilis was $2 \mathrm{mg} / \mathrm{ml}$ and against C.albicans was $2.2 \mathrm{mg} / \mathrm{ml}$ which was high when compared to the above literature.

The antimicrobial activity of W.tinctoria leaves extract might be related to the action of its antibiotic compounds or may be due to the presence of metabolic toxins. Inhibitory activity of W.tinctoria may be associated with the presence of alkaloids, steroids, saponins and flavonoids (Sridhar et al., 2011). Another research outcome also reports the presence of steroids, triterpenoids, flavonoids and glycosides in W.tinctoria (Reddy et al., 1999) as responsible agents for antimicrobial activity.

This suggests that these components may also provide antimicrobial activity against certain microorganisms and provides a plausible explanation for the higher antimicrobial activity of these extracts. Previous reports showed that several phytoconstituents like flavonoids (Tsuchiya et al., 1996), phenols (Mason and Wasserman, 1987), terpenoids (Scortichini and Pia Rossi; 1991) etc., are effective antimicrobial substances against a wide range of microorganisms. The significance of these compounds is that these could be used as substitutes for synthetic antibiotics for the treatment of various diseases.

Kaneria et al., (2009) tested petroleum ether, methanol, aqueous and ethyl acetate leaf, stem and fruit extracts of Wrightia tomentosa (Apocynaceae) against various bacteria. Highest antibacterial activity was shown by ethyl acetate stem extract of Wrightia tomentosa against S.aureus. 
Table.1

\begin{tabular}{|c|c|c|c|}
\hline \multirow[t]{2}{*}{ Name of the phytochemical } & \multicolumn{3}{|c|}{ W.tinctoria } \\
\hline & $\mathrm{HE}$ & $\mathrm{EE}$ & $\mathrm{AE}$ \\
\hline Tannins & + & + & + \\
\hline Alkaloids & + & + & + \\
\hline Flavonoids & + & + & + \\
\hline Phenols & + & + & + \\
\hline Saponins & - & - & + \\
\hline Sterols & + & + & - \\
\hline Quinones & - & - & - \\
\hline Carbohydrates & - & - & + \\
\hline Terpenoids & + & + & + \\
\hline
\end{tabular}

HE denotes Hexane extract, AE denotes Aqueous extract and EE denotes Ethyl acetate extract; + Presence; - Absence

Table.2 Effect of Wrightia tinctoria leaf extracts on bacterial strains

\begin{tabular}{|c|c|c|c|c|c|c|c|c|c|}
\hline \multirow{3}{*}{$\begin{array}{l}\text { Name of the } \\
\text { bacteria }\end{array}$} & \multicolumn{9}{|c|}{ Zone of inhibition in $\mathrm{mm}$} \\
\hline & \multicolumn{3}{|c|}{ HE } & \multicolumn{3}{|c|}{$\mathbf{E E}$} & \multicolumn{3}{|c|}{$\mathbf{A E}$} \\
\hline & $250 \mu \mathrm{g} / 50 \mu \mathrm{l}$ & $500 \mu \mathrm{g} / 50 \mu \mathrm{l}$ & $20 \mu \mathrm{g} / 50 \mu \mathrm{l}$ PC & $250 \mu g / 50 \mu l$ & $500 \mu \mathrm{g} / 50 \mu \mathrm{l}$ & $20 \mu \mathrm{g} / 50 \mu \mathrm{l}$ PC & $250 \mu \mathrm{g} / 50 \mu \mathrm{l}$ & $500 \mu \mathrm{g} / 50 \mu \mathrm{l}$ & $20 \mu \mathrm{g} / 50 \mu \mathrm{l}$ PC \\
\hline B.subtilis & 15 & 26 & 28 & 16 & 25 & 28 & 8 & 12 & 28 \\
\hline B.licheniformis & 16 & 25 & 28 & 13 & 24 & 26 & 13 & 20 & 26 \\
\hline S.pneumoniae & 14 & 24 & 26 & 12 & 20 & 26 & 12 & 18 & 26 \\
\hline E.coli & 15 & 23 & 28 & 13 & 22 & 26 & 10 & 12 & 26 \\
\hline S. sanguinis & 13 & 20 & 25 & 11 & 18 & 25 & 7 & 10 & 26 \\
\hline
\end{tabular}

$\mathrm{HE}$ - hexane extract, EE- ethyl acetate extract, AE- aqueous extract, $\mathrm{PC}$ - Positive control (Ampicillin)

Bacterial strains were spread on agar plates. Different amounts of crude leaf extracts $(250 \mu \mathrm{g}$ and $500 \mu \mathrm{g})$ were placed in the wells. Control contained Ampicillin $(20 \mu \mathrm{g})$ in place of crude leaf extract. The incubation period was $24 \mathrm{~h}$ at $37^{\circ} \mathrm{C}$. Zone of inhibition was measured. 
Table.3 Minimum inhibitory concentration of W. tinctoria crude leaf extracts against bacterial strains

\begin{tabular}{|l|c|c|c|}
\hline \multirow{2}{*}{$\begin{array}{l}\text { Name of the } \\
\text { bacterial strain }\end{array}$} & \multicolumn{3}{|c|}{ Minimum inhibitory concentration (mg/ml) } \\
\cline { 2 - 4 } & HE & EE & AE \\
\hline B.subtilis & 2 & 2.2 & 4.5 \\
\hline B.licheniformis & 2.2 & 2.6 & 3 \\
\hline S.pneumoniae & 2.3 & 3 & 3.2 \\
\hline E.coli & 2.5 & 2.8 & 4.4 \\
\hline S.sanguinis & 3 & 3.2 & 4.6 \\
\hline
\end{tabular}

HE -hexane extract, EE- ethyl acetate extract, AE- aqueous extract; Microbial strains were spread on agar plates. Different concentrations (1$5 \mathrm{mg} / \mathrm{ml})$ of crude leaf extracts were placed in the wells. Control contained Ampicillin $(20 \mu \mathrm{g} / 50 \mu \mathrm{l})$ in the place of crude leaf extracts. Zone of inhibition was measured and minimum inhibitory concentration of crude leaf extracts was determined.

Table.4 Effect of W. tinctoria leaf extracts on fungal strains

\begin{tabular}{|c|c|c|c|c|c|c|c|c|c|}
\hline \multirow{3}{*}{$\begin{array}{l}\text { Name of } \\
\text { the } \\
\text { fungi }\end{array}$} & \multicolumn{9}{|c|}{ Zone of inhibition in $\mathrm{mm}$} \\
\hline & \multicolumn{3}{|c|}{ HE } & \multicolumn{3}{|c|}{$\mathbf{E E}$} & \multicolumn{3}{|c|}{$\mathbf{A E}$} \\
\hline & $250 \mu \mathrm{g} / 50 \mu \mathrm{l}$ & $500 \mu g / 50 \mu l$ & $20 \mu \mathrm{g} / 50 \mu \mathrm{l}$ PC & $250 \mu \mathrm{g} / 50 \mu \mathrm{l}$ & $500 \mu \mathrm{g} / 50 \mu \mathrm{l}$ & $20 \mu \mathrm{g} / 50 \mu \mathrm{l}$ PC & $250 \mu \mathrm{g} / 50 \mu \mathrm{l}$ & $500 \mu \mathrm{g} / 50 \mu \mathrm{l}$ & $20 \mu \mathrm{g} / 50 \mu \mathrm{l}$ PC \\
\hline A.flavus & 12 & 20 & 24 & 10 & 19 & 24 & - & 8 & 24 \\
\hline A.niger & 14 & 22 & 26 & 12 & 18 & 26 & 12 & 16 & 26 \\
\hline C.albicans & 16 & 25 & 28 & 14 & 23 & 28 & 12 & 20 & 28 \\
\hline
\end{tabular}

$\mathrm{HE}$ - hexane extract, EE- ethyl acetate extract, AE - aqueous extract

Fungal strains were spread on agar plates. Different amounts of crude leaf extracts $(250 \mu \mathrm{g}$ and $500 \mu \mathrm{g})$ were placed in the wells. Control contained Flucanozole $(20 \mu \mathrm{g})$ in place of crude leaf extract. The incubation period was $24 \mathrm{~h}$ at $37^{\circ} \mathrm{C}$. Zone of inhibition was measured 
Table.5 Minimum inhibitory concentration of W.tinctoria leaf extracts against fungal strains

\begin{tabular}{|l|c|c|c|}
\hline \multirow{2}{*}{$\begin{array}{l}\text { Name of the } \\
\text { fungal strain }\end{array}$} & \multicolumn{3}{|c|}{ Minimum inhibitory concentration } \\
\cline { 2 - 4 } & HE & EE & AE \\
\hline A.flavus & 3 & 3.1 & 4.8 \\
\hline A.niger & 2.8 & 2 & 3.4 \\
\hline C.albicans & 2.2 & 2.2 & 3 \\
\hline
\end{tabular}

HE -hexane extract, EE- ethyl acetate extract, AE- aqueous extract

Microbial strains were spread on agar plates. Different concentrations $(1-5 \mathrm{mg} / \mathrm{ml})$ of crude leaf extracts were placed in the wells. Control contained Flucanazole $(20 \mu \mathrm{g} / 50 \mu \mathrm{l})$ in the place of crude leaf extracts. Zone of inhibition was measured and minimum inhibitory concentration of crude leaf extracts was determined.

Fig.1 Antibacterial activity of HE of W.tinctoria exhibiting maximum zones of inhibition

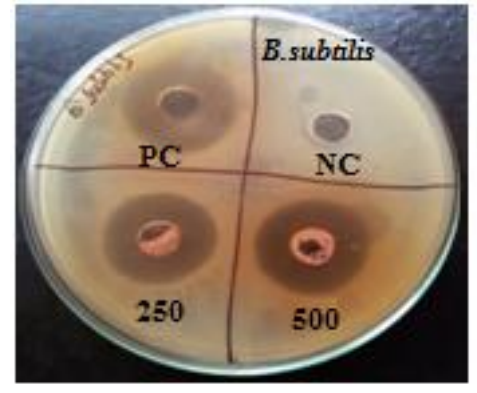

B.subtilis

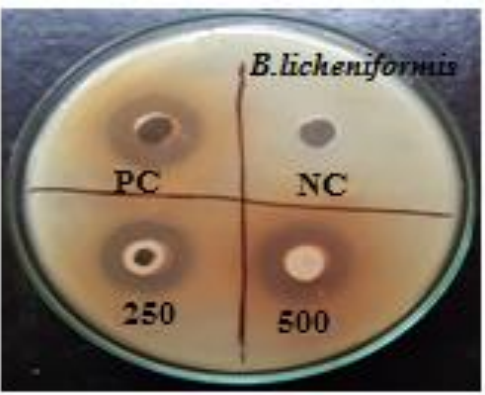

B.licheniformis

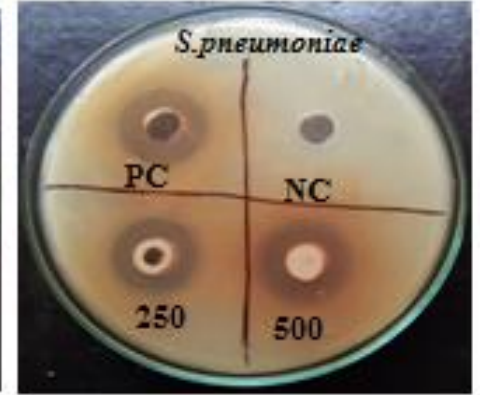

S.pneumoniae

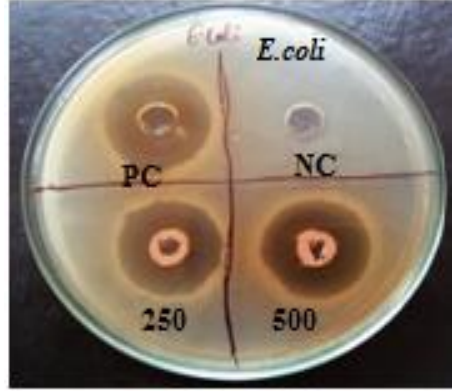

E.coli

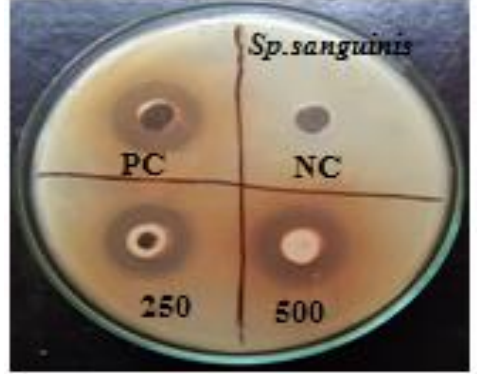

S.sanguinis 
Fig.2 Antifungal activity of HE of W.tinctoria exhibiting maximum zones of inhibition

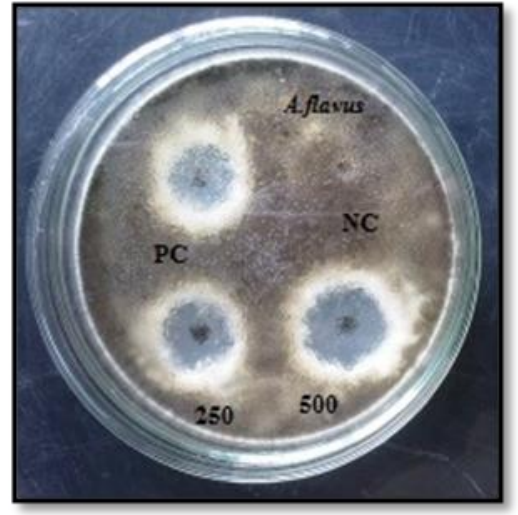

A.flavus

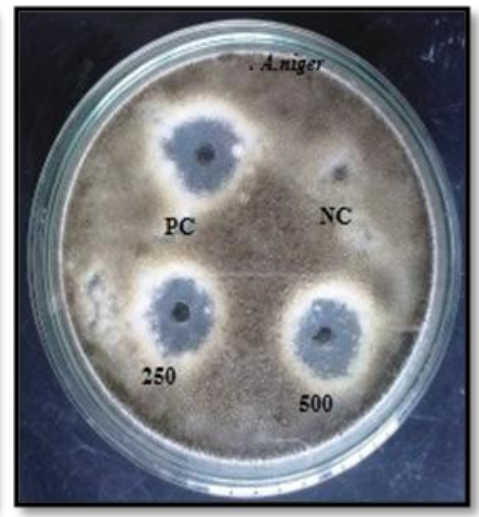

A.niger

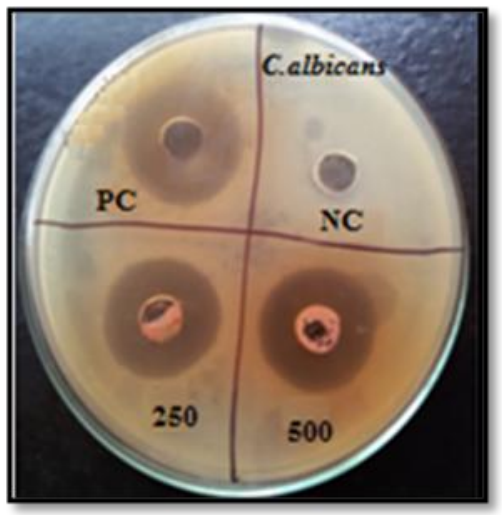

C.albicans
In vitro antifungal activities of Catharanthus roseus, Nerium oleander and Tabernaemontana divaricata (Apocynaceae) leaf extracts were evaluated using human fungal pathogen Candida albicans. The aqueous, petroleum ether, methanol and ethyl acetate leaf extracts of all the above plants showed potential activity against C.albicans. Methanol and ethyl acetate leaf extracts of Catharanthus roseus exhibited a MIC of 4 $\mathrm{mg} / \mathrm{ml}$. Aqueous leaf extract of Nerium oleander exhibited a MIC of $2 \mathrm{mg} / \mathrm{ml}$ and methanol extract $\quad 4 \mathrm{mg} / \mathrm{ml}$ whereas Tabernaemontana divaricata aqueous, petroleum ether and methanol extracts exhibited MIC of $2 \mathrm{mg} / \mathrm{ml}$ (Wankhede et al., 2013).

Antimicrobial potential of Amaranthus viridis ethanolic leaf extract was tested against two Gram positive bacterial strains, Staphylococcus aureus and Bacillus subtilis, and four Gram negative bacterial strains viz, Proteus vulgaris, Peudomonas picketii, Klebsiella pneumoniae and Escherichia coli and against five different strains of fungal species, Fusarium solani, Alternaria species, Aspergillus flavus green, Aspergillus niger and Aspergillus fumigatus. At a concentration of $25 \mathrm{mg} / \mathrm{ml}$, the zones of inhibition ranged between $10.1 \pm 0.01$ to $13.1 \pm 0.06$, with the maximum zone of inhibition observed against Bacillus subtilis. It was reported that Amaranthus viridis had moderate antifungal activity (41-51\%) against Alternaria species while low activity (below 40\%) against Aspergillus flavus green, Aspergillus niger and Aspergillus fumigatus (Sumaira et al., 2016).

Srinivasan et al (2001) have suggested that demonstration of antimicrobial activity against both Gram positive and Gram negative bacteria may be indicative of the presence of broad spectrum antibiotic compounds. Demonstration of broad spectrum of antibacterial activity by various extracts of W.tinctoria may help to discover new chemical classes of antibiotic substances that could serve as selective agents for infectious disease chemotherapy and control. This investigation has opened up the possibility of the use of these two plants in antimicrobial drug development for human application.

The results obtained in this present study were observed to be in accordance with previous reports that the antimicrobial activity of W.tinctoria might be due to the presence of active phytochemical compounds. The present study has revealed that among all the tested leaf extracts, HE of W.tinctoria was more 
effective against all the tested bacteria and fungi. Therefore, HE of W.tinctoria might be a source of new antibiotic compounds and has a significant scope for antimicrobial research.

Earlier study on phytochemical screening of $\mathrm{HE}, \mathrm{EE}$ and $\mathrm{AE}$ of W.tinctoria has provided a foundation for identification of active ingredients present in the crude leaf extracts. The results of the present research support further analysis of HE of W.tinctoria R.Br. for purification in order to isolate the specific active constituent and to perform toxicology studies and in vivo studies to identify its utilization in herbal drug formulations.

In conclusion, based on these results, it can be concluded that, the two solvents and aqueous leaf extracts of Wrightia tinctoria exhibited a broad range of antimicrobial activity to varying degrees. Particularly, hexane leaf extract showed significant antimicrobial activity and could be used as an antimicrobial agent in new drugs for therapy. So, further evaluation and analysis of phytochemical compounds are needed in order to utilize them as novel antimicrobial agents. Hence, the present study justifies the claimed uses of Wrightia tinctoria in the traditional system of medicine to treat various infectious diseases caused by microbes.

\section{References}

Adesina, G.O., Onaolapo, J.A, Ehinmido, J.O. and Odama, L.E. 2010. Phytochemical and antimicrobial studies of the ethyl acetate extract of Alchornea cordifolia leaf found in Abuja, Nigeria. J. Med. Plants Res., 4 (8): 649 - 658.

Adesokan, A.A., Akanji, M.A. and Yakubu, M.T. 2007. Antibacterial potentials of aqueous extract of Enantia chlorantha stem bark. African J. Biotechnol., 6(22): 2502-2505.

Akinmoladun, A.C., Ibukun, E.O., Afor, E.,
Obuotor, E.M. and Farombi, E.O.2007.

Phytochemical constituent and antioxidant activity of extract from leaves of Ocimum gratissimum. Scientific Research and Essays, 2: 163 $-166$.

Bigoniya, P., and Rana, A.C. 2010. Protective effect of Wrightia tinctoria bark triterpenoid fraction on carbon tetrachloride-induced acute rat liver toxicity. Iranian J. Pharmacol. Therapeutics, 9: 55-62.

Chanda, S., Kaneria, M. and Nair, R. 2011. Antibacterial activity of Psordalea corylifolia L seed and aerial parts with various extraction methods. Res. J. Microbiol., 60: 124 - 131.

Cohen, M.L., 1992. Epidemiology of drug resistance: implications for a postantimicrobial era. Sci., 257:1050-1055.

Doughari, J.H., and Manzara, S. 2008. In vitro antibacterial activity of crude leaf extracts of Mangifera indica Linn. African J. Microbiol. Res., 2: 067 - 072.

Edeoga, H.O., Okwu, D.E. and Mbaebie, B.O. 2005. Phytochemical constituents of some Nigeria medicinal plants. African Journal of Biotechnology 4 (7): 685 688.

Elizabeth, M., Adrien Szekely Johnson., David, W. and Warnock. 1999. Comparison of e-test and broth microdilution methods for antifungal drug susceptibility testing of molds. $J$. Clin. Microbiol., 37(5): 1480-1483.

Ghosh, D., Thejmoorth, P. and Veluchamy, G.1985. Anti-inflamatory, analgesic and antipyretic activities of 777 oil-a siddha medicine. Bull. Med. Ethnobot. Res., 6(24): 141-154.

Kaneria, M., Baravalia, Y., Vaghasiya, Y. and Chanda, S. 2009. Determination of antibacterial and antioxidant potential of some medicinal plants from Saurashtra region, India. Indian J. Pharmaceutical Sci., 71(4): 406 - 412. 
Kannan, P., Shanmugavadivu, B., Petchiammal, C. and Hopper, W. 2006. In vitro antimicrobial activity of Wrightia tinctoria leaf extracts against skin microorganisms. Acta Botanica Hungarica, 48: 323-329.

Krishnamurthi, J.R., Kalaimani, S. and Veluchamy, G. 1981. Clinical study of Vetapalai (Wrightia tinctoria) oil in the treatment of Kalanjagapadai (Psoriasis). J. Res. Ayurveda and Siddha, 2(1): 5866.

Lewis, W.H., and Elvin Lewis, M. 1995. Medicinal plants as sources of new therapeutics. Annals of the Missouri Botanical Garden, 82, 16 - 24.

Masibo, M., and He, Q. 2009. In vitro antimicrobial activity and the major polyphenol in leaf extract of Mangifera indica L. Malaysian J. Microbiol., 5(2): $73-80$.

Mason, T.L., and Wasserman, B.P. 1987. Inactivation of red beet betaglucan synthase by native and oxidized phenolic compounds. Phytochemistry, 26 (8): 2197- 2202.

Moorthy, K., Aparna Aravind., Punitha, T., Vinodhini, R., Suresh, M. and Thajuddin, N. 2012. In vitro Screening of antimicrobial activity of Wrightia tinctoria (Roxb.) R. Br. Asian J. pharmaceutical and Clin. Res., 5 (4): 54- 58.

Mungole, A., Day, S., Kamble, R., Kanfade, H., Chaturvedi, A. and Zanwar, P. 2010. Active phytochemical potentiality of invitro regenerated plantlets of Canscora decurrens (Dalzell). Indian J. Sci. Technol., 3 (6): $679-683$.

Murray, P.R., Baron, E.J.,Pfaller, M.A., Tenover, F.C. and Yolken, H.R. 1995. Manual of Clinical Microbiology. Sixth Ed. ASM Press, Washington DC. Pp. 15-18.

Muruganadam, A.V., Bhattacharya, S.K., Ghosal, S. 2000. Indole and flavonoid constituents of Wrightia tinctoria and W. tomentosa and W. coccinea. Indian J. Chemistry, 39b (2):125-131.

Olurinola, P.F., 1996. A laboratory manual of pharmaceutical microbiology. Idu, Abuja, Nigeria. Pp. 69-105.

Perez, C., Pauli, M. and Bazerque, P. 1990. An antibiotic assay by agar-well diffusion method. Acta Biologiae et Medicinae Experimentalis, 15, 113-115.

Prasad, R.N., Viswanathan, S., Devi, J.R., Nayak, V., Swetha, V.C., Archana, B.R. Parathasarathy, N. and Rajkumar, J. 2008. Preliminary phytochemical screening and antimicrobial activity of Samanea saman. J. Med. Plants Res., 3 (1): $045-048$.

Rasooli, I., Shayeh, S., Taghizadeh, M. and Astaneh, S.D.A. 2008. Phytotherapeutic prevention of dental biofilm formation. Phytotherapy Res., 22, 1162 - 1167.

Reddy, Y.S., Venkatesh, S., Ravichandran, T., Suburajau, T. and Sueresh, B. 1999. Pharmacognostical studies on Wrightia tinctoria bark. Pharma Biol. 37(4): 291295.

Scortichini, M., and Pia Rossi, M. 199. Preliminary in vitro evaluation of the antimicrobial activity of terpenes and terpenoids towards Erwinia amylovora (Burrill). J. Appl. Bacteriol., 71, 109 112.

Sridhar, S., Kamalakannan, P., Elamathi, R., Deepa, T. and Kavitha, R. 2011. Studies on antimicrobial avtivity, physiochemical and phytochemical analysis of Wrightia tinctoria. Int. J. Pharmaceutical Res. Development, 3 (8):139-144.

Srinivasan, D., Perumalsamy, L.P., Nathan, S. and Suresh, T. 2001. Antimicrobial activity of certain Indian medicinal plants used in folkloric medicine. $J$. Ethnopharmacol., 74 (3): 217 -220.

Subhashini Devi, P., Satyanarayana, B. and Tarakeswara Naidu, M. 2014. 
Phytochemical screening for secondary metabolites in Boswellia serrata Roxb. and Wrightia tinctoria (Roxb.) R.Br. Notulae Scientia Biologicae, 6(4): 74477.

Sumaira, S.A., Maimoona, S., Sajid Raza, S. and Malik, S.A. 2016. Analysis of antimicrobial activity of medicinal plant Amaranthus viridis. Int. J. Innovation and Scientific Res., 20(2): 494-499.

Tripathi, P. and Patel, J.R. 2007. Hepatoprotective activity of Ficus lacor bucham. Int. J. Pharmacol. Biol. Sci., 1(1): 33-35.

Truiti, M. C. T., Sarragiotto, M. H, Filho, B. A. A., Nakamura, C. V. and Filho, B. P.D. 2003. In vitro antibacterial activity of a 7-O-b-D-glucopyranosylnutanocoumarin from Chaptalia nutans (Asteraceace). The Memórias do Instituto Oswaldo Cruz, Rio de Janeiro. 98 (2): 283-286.

Tsuchiya, H, Sato, M., Miyazaki, T., Fujiwara, S., Tanigaki, S., Ohyama, M., Tanaka, T. and Iinuma,M. 1996. Comparative study on the antibacterial activity of phytochemical flavanones against methicillin-resistant Staphylococcus aureus. J. Ethnopharmacol., 50, 27- 34.

Vedhanarayanan, P. Unnikannan, P. and Sundaramoorthy, $\quad$ P. 2013. Antimicrobial activity and phytochemical screening of Wrightia tinctoria (Roxb.) R.Br. J. Pharmacognosy and Phytochemistry, 2(4): 123 - 125.

Veerapur V.P., Palkar, M.B., Srinivasa, H., Kumar, M.S., Patra, S., Rao, P.G.M. and Srinivasan, K.K. 2004. The effect of ethanol extract of Wrightia tinctoria bark on wound healing in rats. $J$. Natural Remedies, 4(2): 155- 159.

Wankhede, S., Madhushree Madhumita Routh., Sandeep Balsingh Rajput. and Sankuny Mohan Karuppayil. 2013. Antifungal properties of selected plants of Apocynaceae family against the human fungal pathogen Candida albicans. Int. Curr. Pharmaceutical J., 2(7): $122-125$.

\section{How to cite this article:}

Sravanthi Maddila and Hemalatha, K.P.J. 2017. Phytochemical Screening and In vitro Antimicrobial Properties of Crude Leaf Extracts of Wrightia tinctoria R.Br. Int.J.Curr.Microbiol.App.Sci. 6(1): 707-720. doi: http://dx.doi.org/10.20546/ijcmas.2017.601.085 